\title{
POSITIVE-WORKING RESIST FOR S R LITHOGRAPHY BASED ON CROSSLINKING OF PHENOLIC POLYMER BY VINYL ETHER CROSSLINKER.
}

T. Yamaoka, T. Suzuki. Department of Image Science, Faculty of Engineering, Chiba University, Yayoicho, Inageku, Chiba, 263, Japan, T. Taguchi, Y. Yamashita Tsukuba Research Lab., SORTEC Co., Wadai, Tsukuba, 300-42, Japan.

\section{Introduction}

SR lithography is expected to be one of the promising methods for pattern transfer in nanoscopic resolution. However, unlike the UV lithography, positivetone SR resists is meeting the requirement of $0.15 \mu \mathrm{m}$ pattern formation, are still not available, where as negative-tone $S R$ resists with both high sensitivity and high resolution have been developed based on acid catalyzed amplification mechanism.' In the present study, a series of the positive-tone resists for nanolithography based on a novel mechanism were prepared and evaluated their properties as the SR lithography.

\section{Experimental}

Poly(p-hydroxystyrene)(PHS), commercially available from Maruzen Petrochemical Co.), and poly(styrene-co-acrylic acid)(PSAA) from Johnson Co. were used as base polymers. Photoacid generator (PAG), diphenyiodonium triflate was available from Tokyo Kasei Co.. 2,2'-Bis(4-(2-vinyloxyethoxy)phenyl)propane(BPA-DEVE) was synthesized from bisphenol $A$ and chroloethylvinyl ether.

The three component resists consist of base polymer, bifunctional vinyl ether monomer, and PAG. The compositions are shown in Table 1.

The SR resist layer with about $1 \mu \mathrm{m}$ thickness was formed by spin-coating the solution on a Si wafer, followed by prebaking at $100-120^{\circ} \mathrm{C}$. After the prebake, the layer was made insoluble in common organic solvents as well as aqueous base developer(2.38\% TMAH) because the base polymer was crosslinked by the bifunctional vinyl ether monomers. The crosslinks are achieved by an addition of vinyl ether with the acidic hydroxyl groups in the base polymer via the formation of acetal bonds, which are easily de-crosslinked in the presence of acid and appropriate thermal energy. ${ }^{21}$ The exposure of The resist layers on the Si substrates were exposed to X-ray from beam line BL-A1 of SORTEC SR through a $\mathrm{X}$-ray mask prepared by SiN/Ta.

Table 1 Composition of positive-tone $\mathbf{S} R$ resist.

\begin{tabular}{|l|lll|}
\hline Base Polymer & Poly(hydroxystyrene) & 0.5 & $\mathbf{g}$ \\
\hline Cromslinker & Bls(vinyloxyethyl phenoxy) methane & 0.02 & $\mathbf{g}$ \\
\hline Photoacid generator & Diphenyliodonium triflate & $0.025 \mathrm{~g}$ \\
\hline
\end{tabular}


Results and Discussion

Dissolution rates of the resist layers before and after exposure were measured as function of PB temperature for the resists consisting of PHS and PSAA(Figure $1 \mathrm{a}$ and $\mathrm{lb}$ ). The dissolution rates after $\mathrm{PB}$ starts to decrease at $100{ }^{\circ} \mathrm{C}$ and $80^{\circ} \mathrm{C}$ for PHS and PSAA, respectively, and the dissolution rate after prebaking at $120 \mathrm{r}$ is almost negligible for the both resists. On the other hand, the dissolution rate of the exposed resist layer is almost kept constant at the temperature higher than $60^{\circ} \mathrm{C}$. Figure lc shows the fraction of crosslinking as function of

prebaking time. The fraction for PSAA is higher than PHS at $10 \mathrm{~min}$. This fact means that the rate of crosslinking depends on the acidity of acid group in the base polymer.
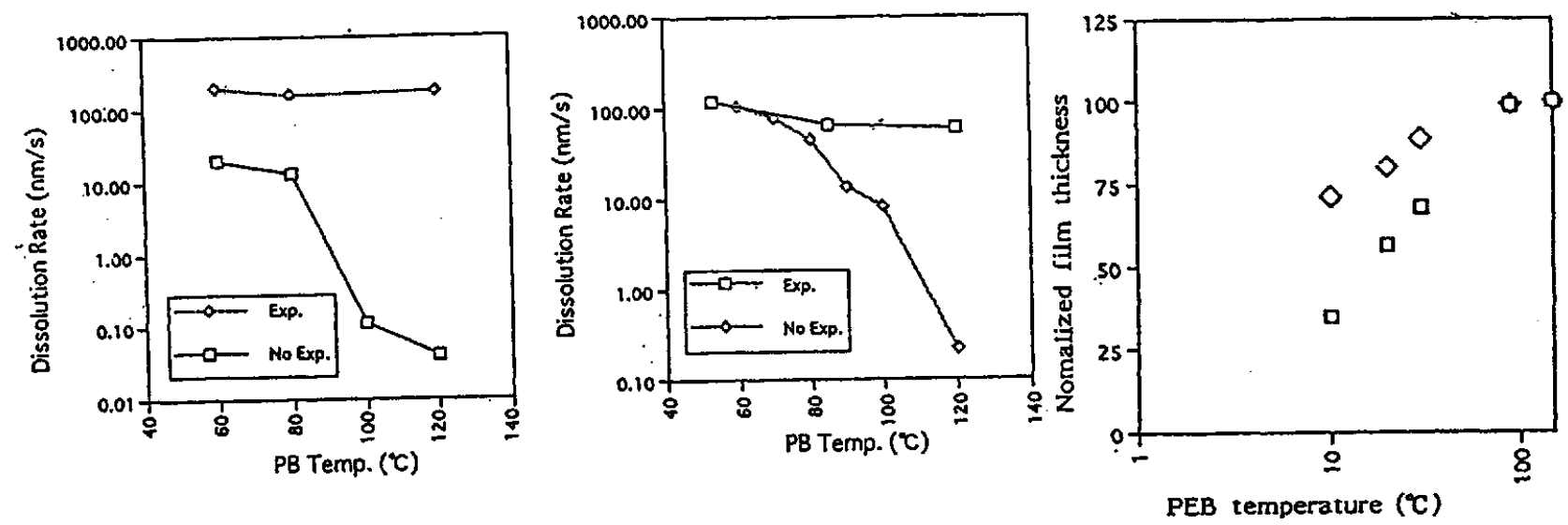

Fig.1 Dissolution rates of the PHS-based (a) and PSAA-based (b) resist layers before and after exposure as function of baking temperature. Nomalized film thickness as function of prebake temperature (c).

In Figure 2a, FTIR spectrum of the PHS-based resist film, and the change due to the prebaking at $120^{\circ} \mathrm{C}$. Figure $2 \mathrm{~b}$ shows a difference spectrum incorpolating the prebaking. These spectra for the resist films suggest that the reaction of the vinyloxy and the hydroxy groups proceeds in similar rate to those of the dissolution rate.

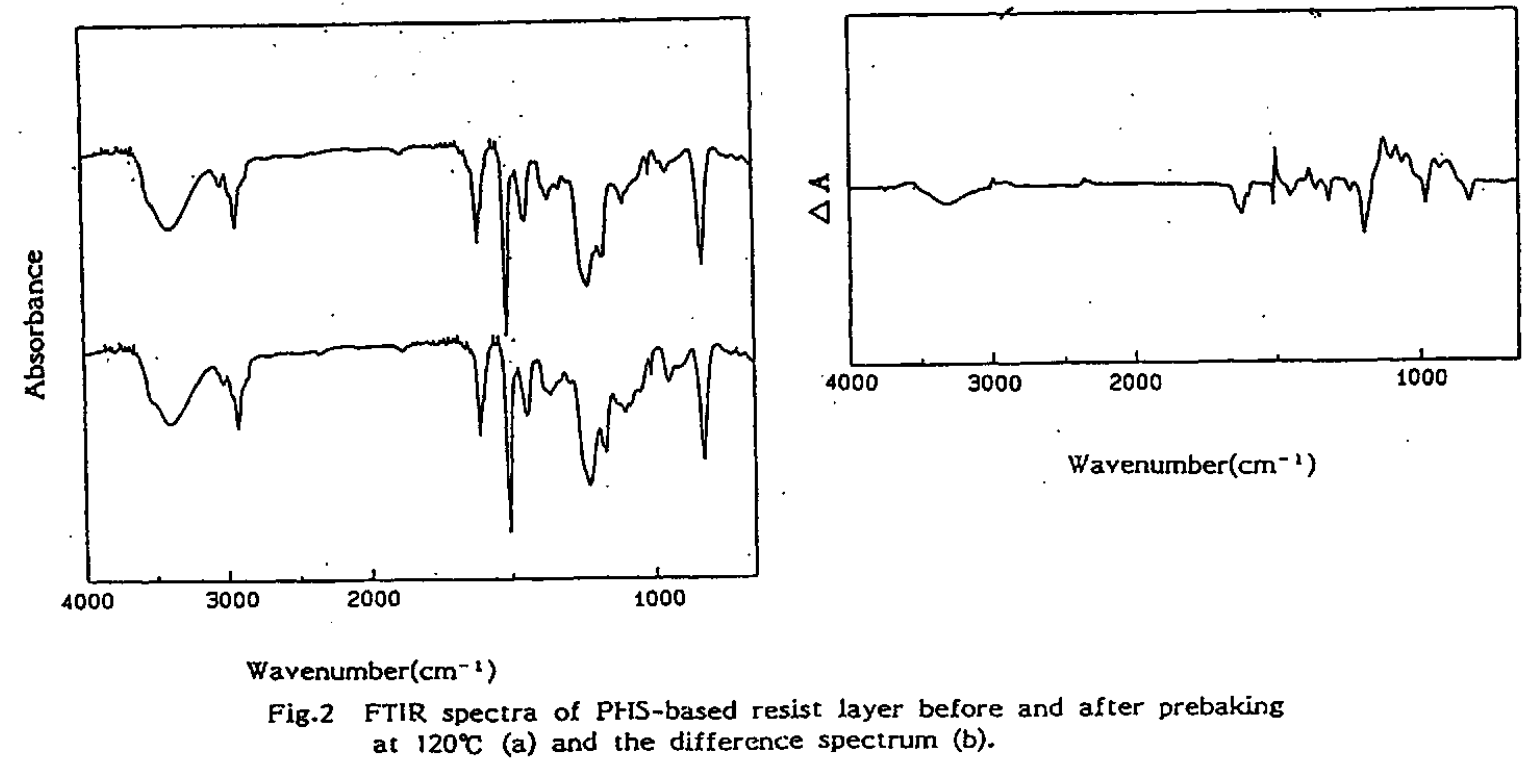


Figure 3 (a) and 3(b) show the sensitivity curves and their dependence on the PEB temperature for the both resist layers. The sensitivity for these positiveworking resists layers is relatively high from 30 to $100 \mathrm{~mJ} / \mathrm{cm}^{2}$, depending on the PEB temperature.
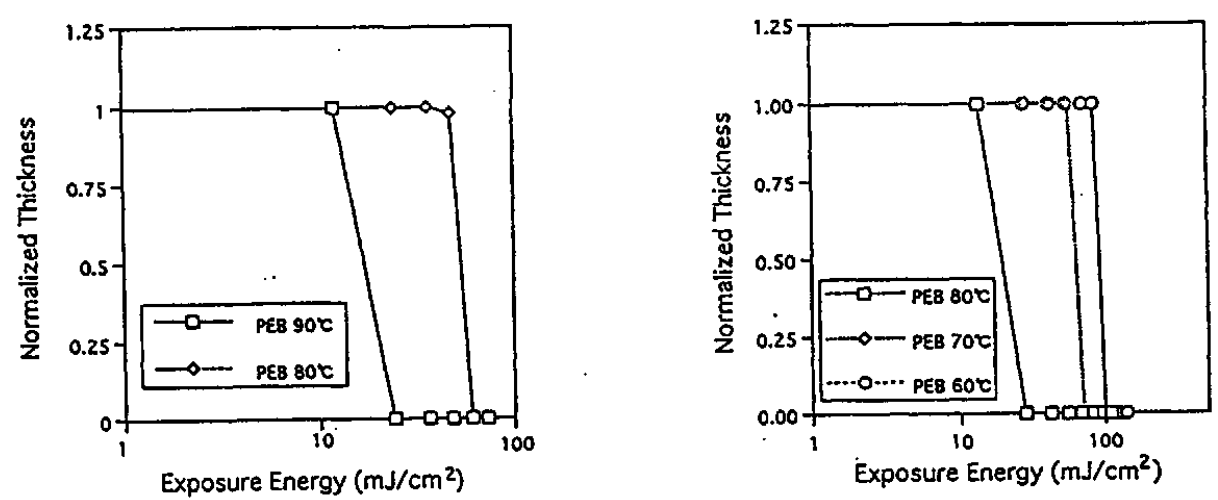

Fig.3 Sensitivity curves and the effect of PEB temperature for PHB-based (a) and PSAA-based (b) resist layers.

In addition, these polymers have gamma values higher than 10. SEM pictures (Figure 4) of the patterns transferred by $\mathrm{X}$-ray show that $0.35 \mu \mathrm{m} \mathrm{L/S}$ patterns are clearly resolved with $40 \mathrm{~mJ} / \mathrm{cm}^{2}$ exposure energy.

Mechanism to give the positive-working behavior is proposed as reaction Scheme shown below.
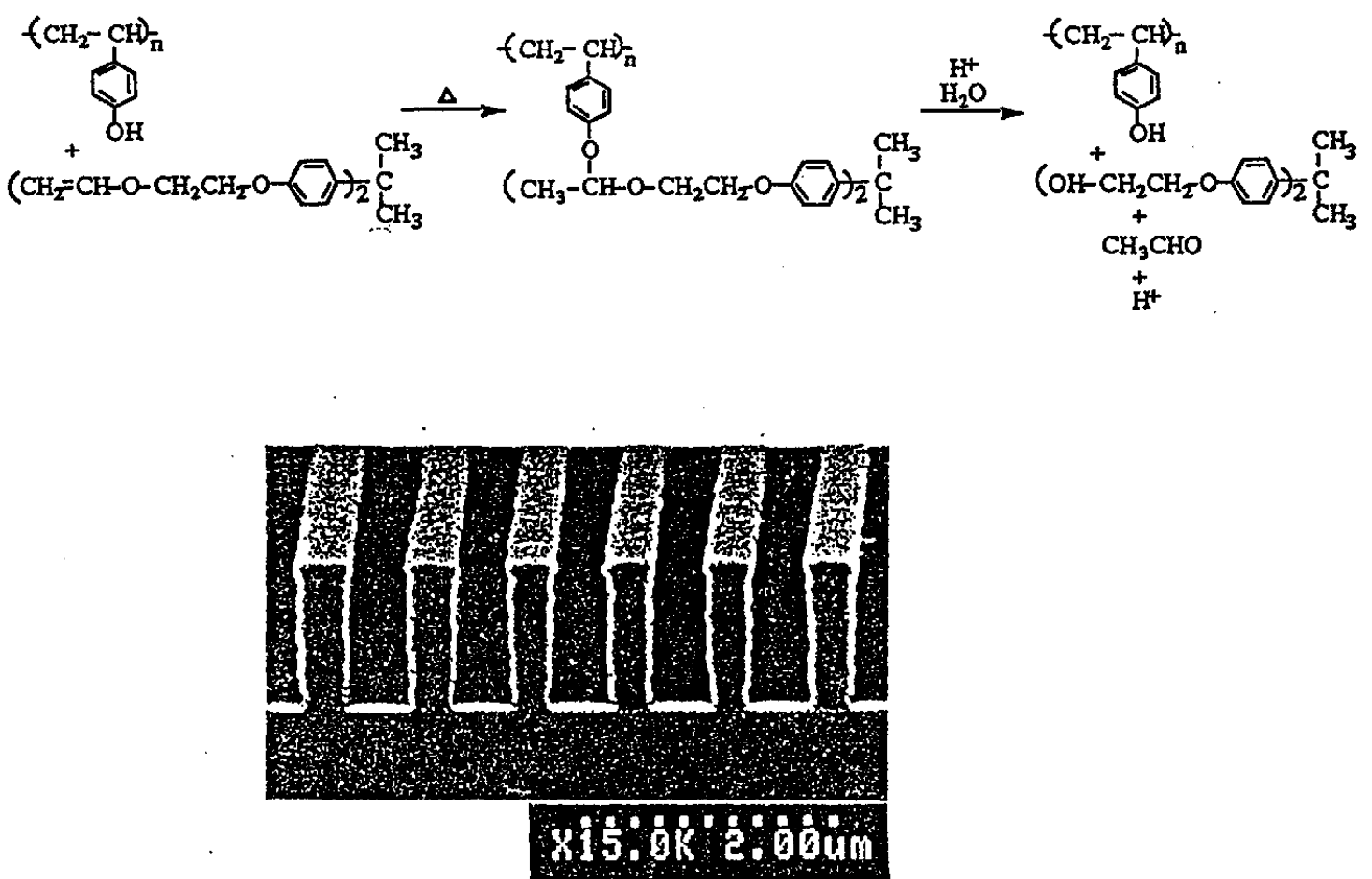

Fig.4 A SEM picture of $0.35 \mathrm{~L} \& \mathrm{~S}$ pattern transferred by SR exposure. 
The $G$ value of the acid generation from $\mathrm{PAG}\left(\mathrm{DPI}^{+} \mathrm{CF}_{3} \mathrm{SO}_{3}{ }^{-}\right)$in the resist films due to SR irradiation was measured. Additionally, quantum yield for Deep UV light for comparing the difference between SR and Deep UV light. The generated acid was determined by measuring the absorbance change of acid indicator existing in the resist film. The relation between the concentration of acid and absobance of the indicator at $628 \mathrm{~nm}$ that is given in Figure 5, was used to quantitative determination of the acid in the resist films. The plots of acid generation from PAG as function of the absorbed dose are demonstrated in Figure $6 \mathrm{a}$ and $6 \mathrm{~b}$. The plotted curves are different for SR and Deep UV light. The $G$ value and the quantum yield were determined as 7.2 and 0.20 , respectively. The initial process for these light sources may be different each other. The mechanism of acid generation for these light sources will be discussed.
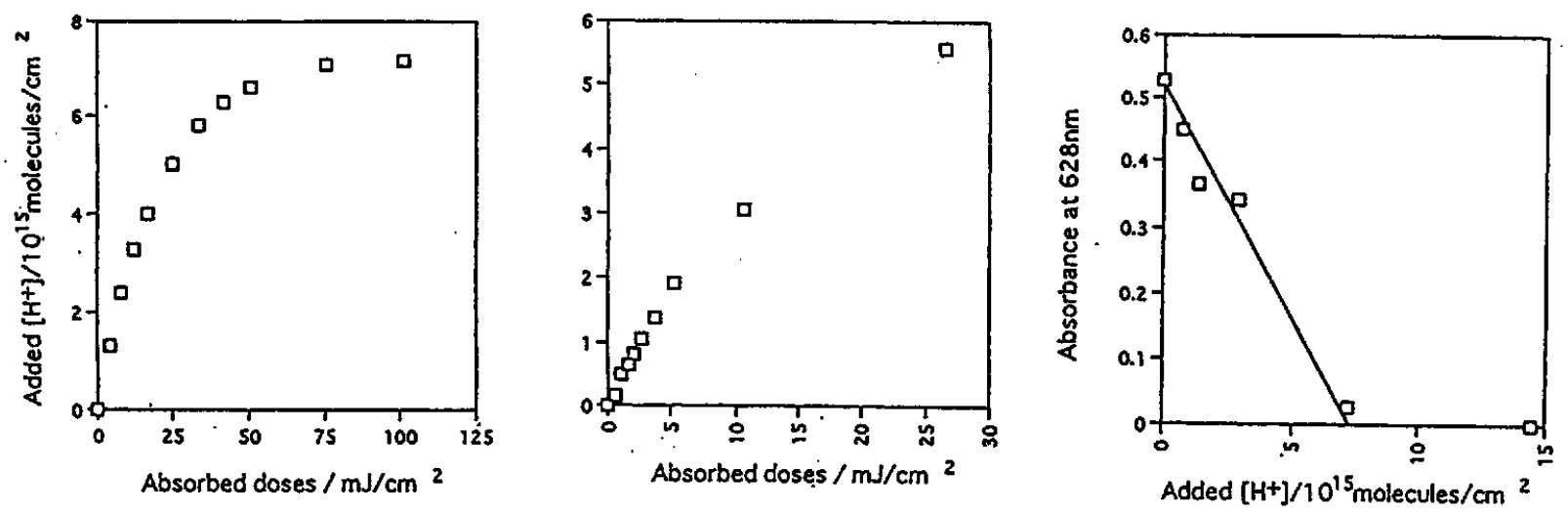

Fig.5 A plot of acid species generated from PAG as function of absorbed dose of $248 \mathrm{~nm}$ UV light (a) and SR (b), respectively. The amount of acid was determined by measuring absorbance at $628 \mathrm{~nm}$ peak of the acid indicator using the calibration line (c).

\section{Reference:}

1) H.Ito and C.G.Wilson: Polym. Eng. Sci., 23(1983) 1012.

2) S.Moon, K.Naitoh, and T. Yamaoka: Chem. Mater., 5(1993) 1315.

K.Kamenosono, K.Naitoh, S.Kondo, A.Umehara, T.Yamaoka:Polym. Adv. Technol, 5 (1993) 499. S.Moon, K.Kamenosono, S.Kondo, A.Umehara, T. Yamaoka: Chem. Mater., 6 (1994) 1854. 